\title{
Disturbed integrin expression in the vascular media in CADASIL
}

\author{
Dorota Dziewulska ${ }^{1,2}$, Ewelina Nycz ${ }^{3}$ \\ ${ }^{1}$ Department of Neurology, Medical University of Warsaw, Warsaw, ${ }^{2}$ Department of Experimental and Clinical Neuropathology, \\ Mossakowski Medical Research Institute, Polish Academy of Sciences, Warsaw, ${ }^{3}$ Department of Neurology, Medical Center, \\ Lancut, Poland
}

\begin{abstract}
CADASIL (cerebral autosomal dominant arteriopathy with subcortical infarcts and leukoencephalopathy) is an inherited angiopathy characterized by degeneration and loss of vascular smooth muscle cells (VSMCs) of still unknown pathomechanism. Many functions of VSMCs, such as adhesion, apoptosis, contraction, differentiation, migration, and proliferation are determined by integrins - surface adhesion receptors involved in binding and interactions between cells and extracellular matrix (ECM). Since integrins play such an important role in VSMCs biology, disturbances in their expression may influence myocytes behavior and fate in CADASIL. In this study, we focused on the most important compounds of VSMCS integrins: subunits $\alpha_{4}, \beta 1$, and $\beta_{3}$ in an attempt to elucidate their immune expression in the arterial media of CADASIL patients. The immunohistochemistry revealed a decreased expression of integrin $\beta 1$ subunit $(p<0.001)$ but similar to the control expression of integrin subunits $\alpha_{4}$ and $\beta_{3}$. Decreased $\beta 1$ immunoreactivity was observed in capillary vessels, arterioles, and small arteries. The abnormal immune expression of integrin $\beta 1$ subunit was found even in microvessels without microscopically noted degenerative changes, which suggests that this is an early phenomenon in CADASIL. Since integrin $\beta 1$ subunit is a compound of 10 heterodimer integrin receptors, its disturbed expression may significantly influence VSMCs biology leading to myocytes degeneration and loss via anoikis - a type of apoptotic cell death due to loss or inappropriate cell adhesion to ECM.
\end{abstract}

Key words: CADASIL, integrin, microangiopathy, tunica media, vascular smooth muscle.

\section{Introduction}

CADASIL (cerebral autosomal dominant arteriopathy with subcortical infarcts and leukoencephalopathy) is an inherited angiopathy due to NOTCH3 mutations and it is characterized by degeneration and loss of vascular smooth muscle cells (VSMCs) and pericytes. In spite of intensive research studies, the relationship between NOTCH3 defects and the pathomechanism of destruction of small blood vessels in CADASIL is still unknown.
VSMCs are cells with a high degree of plasticity which can undergo reversible phenotypic changes in response to environmental stress and vascular injury. Disturbances both in interactions between vessel wall cells and extracellular matrix (ECM) as well as in intercellular communication play an important role in control of VSMCs behavior. This exchange of information occurs through specialized types of cell surface receptors: mainly integrin receptors but also discoidin domain receptors, cell 
surface proteoglycan receptors, and the hyaluronan receptor CD44a [25].

According to their name, integrins integrate ECM with cells and cells together. An integrin receptor is composed of two subunits: $\alpha$ and $\beta$. Subunit $\alpha$ is responsible for the receptor binding with ligand and determines integrin specificity while subunit $\beta$ takes part in interaction with cytoskeletal proteins and determines the receptor function [5]. In cerebral blood vessels, integrins are also involved in many other important functions such as:

- mechanotransduction - a process of converting mechanical stimuli such as press or stretching to intracellular signals resulting in a specific gene expression,

- regulation of vasomotor response: contraction (integrins $\alpha 1 \beta 1$ and $\alpha 5 \beta 1$ ) and relaxation (integrin $\alpha v \beta 3)$ of the vessel [15],

- regulation of vessel permeability by modification of cadherins in endothelial adherent junctions and by contraction of collagen fibers in ECM (integrin $\alpha 2 \beta 1$ ) [20],

- regulation of VSMCs tensegrity (resting tension in VSMC triggered by external mechanical forces, which influences myocyte behavior) [17],

- activation of the cell death program [24]; integrins belong to a group of dependence receptors which lack of activity can lead to cell apoptosis,

- modulation of cells shape by linkage with cytoskeletal actin and reorganization of actin filaments.

In VSMCs, there are 13 combinations of integrins: $\alpha 1 \beta 1, \alpha 2 \beta 1, \alpha 3 \beta 1, \alpha 4 \beta 1, \alpha 5 \beta 1, \alpha 6 \beta 1, \alpha 7 \beta 1$, $\alpha 8 \beta 1, \alpha 8 \beta 1, \alpha V \beta 1, \alpha V \beta 3, \alpha V \beta 5, \alpha 6 \beta 4[15,16]$. Some of them are present in physiologic conditions or on specific myocyte phenotype while others are present only in pathology. On VSMCs, the most abundant integrin subunit is $\beta 1$ subunit which is a compound of 10 heterodimeric receptors.

Since one of the possible causes of VSMCs damage in CADASIL may be a disturbed expression of integrins, we examined in vessels, an immune expression of selected integrins with a key importance for VSMCs biology and fate.

\section{Material and methods}

The study was performed on tissue samples from 10 autopsy brains and 10 skin-muscle biopsies of 20 different patients with CADASIL (Table I). The diagnosis was established on the basis of ultrastructural examination in which deposits of granular osmiophilic material (GOM) in the vessel wall [6] (pathognomonic for the disease) were found. In majority of the cases, genetic tests additionally confirmed CADASIL. Agedmatched control material was composed of 5 normal human brains and 5 normal skin-muscle biopsies. Histopathological and immunohistochemical examinations were performed on formalin-fixed and paraffin embedded sections. On tissue slides immune reactions with antibodies against integrin subunits: $\beta 1$ (Novocastra, NCL-CD29, $1: 40$ ), $\alpha_{4}$ (Santa Cruz Biotechnology, sc-14008, $1: 50$ ) and $\beta_{3}$ (Santa Cruz Biotechnology, sc-52589, $1: 100$ ) were applied. The immunochemistry tests were performed according to a routine streptavidin-biotin-peroxidase method with the using of DAKO LSAB 2 SYSTEM (DAKO, K0675), developed by diaminobenzidine, and assessed by light microscopy.

Intensity of the immune reactions was measured using ImageJ software and gray levels method. In digital photos of slides, color was converted into the gray scale and then intensities of the gray values were measured across the entire vessel wall. Results of the measurements were statistically analyzed with the use of t-Student test for independent variables.

\section{Results}

In CADASIL, preserved VSMCs visible on transverse sections through small arterial vessels often showed around shape with a perinuclear halo (Fig. 1). Such cell appearance is sometimes called "fried egg" look. In small arteries, the round-shaped myocytes were localized mainly in the peripheral part of the media while in arterioles they were present through the whole media thickness.

In CADASIL, immunohistochemistry revealed a decreased expression of the integrin subunit $\beta 1$ in the vascular media in comparison to control material $\left(p<0.001\right.$, CADASIL: SD $39.6 \times 10^{6}$; mean value 61.7 $\times 10^{6}$, control: SD $30.1 \times 10^{6}$; mean value $94.2 \times$ 106) (Fig. 2A). Decreased immunoreactivity to integrin $\beta 1$ was observed in small arteries and arterioles independently of whether the examined vessels revealed or not microscopically noted degenerative changes (Fig. 2D, F). Also capillary vessels (Fig. 2B, C) and some venules showed a diminished expression of integrin $\beta 1$. In arterial vessels with moderately advanced degenerative changes, the expression of integrin $\beta 1$ within tunica media was diminished but still present, and revealed an irregular patchy char- 
Table I. Material - clinical data

\begin{tabular}{|c|c|c|c|c|}
\hline \multicolumn{5}{|c|}{ Clinical data } \\
\hline \multicolumn{5}{|c|}{ Autopsy material } \\
\hline 1 & $\mathrm{~F} / 73$ & \multicolumn{3}{|c|}{ At 68 yo ischemic stroke with left hemiparesis; at 70 yo hemorrhage into the left parieto-occipital area } \\
\hline 2 & $M / 58$ & \multicolumn{3}{|c|}{ Progressing dementia of unknown onset, recurrent ischemic strokes } \\
\hline 3 & $M / 64$ & \multicolumn{3}{|c|}{ At 51 yo ischemic stroke with left hemiparesis; later recurrent bilateral ischemic strokes } \\
\hline 4 & $\mathrm{~F} / 52$ & \multicolumn{3}{|c|}{ Since 40 yo progressing dementia, epilepsy, confirmed NOTCH3 mutation } \\
\hline 5 & $M / 59$ & \multicolumn{3}{|c|}{ Since 53 yo progressing dementia } \\
\hline 6 & $M / 45$ & \multicolumn{3}{|c|}{ Since 40 yo progressing dementia, confirmed NOTCH3 mutation } \\
\hline 7 & $M / 38$ & \multicolumn{3}{|c|}{ Since 33 yo progressing dementia, epilepsy, positive family history } \\
\hline 8 & $\mathrm{~F} / 45$ & \multicolumn{3}{|c|}{$\begin{array}{l}\text { At } 39 \text { yo right hemiparesis with aphasia, later recurrent ischemic strokes, progressing dementia, } \\
\text { positive family history - daughter of patient no. } 7\end{array}$} \\
\hline 9 & $F / 56$ & \multicolumn{3}{|c|}{$\begin{array}{l}\text { Since } 44 \text { yo cognitive disturbances; later recurrent ischemic strokes, progressing dementia; } \\
\text { negative family history }\end{array}$} \\
\hline 10 & $\mathrm{~F} / 58$ & \multicolumn{3}{|c|}{ Migraine, since 48 yo recurrent strokes, confirmed NOTCH3 mutation } \\
\hline \multicolumn{5}{|c|}{ Biopsy material } \\
\hline 1 & $\mathrm{~F} / 51$ & \multicolumn{3}{|c|}{$\begin{array}{l}\text { Since } 41 \text { yo progressing dementia, } 2 \text { ischemic strokes with right hemiparesis and aphasia; } \\
\text { positive family history, confirmed NOTCH3 mutation }\end{array}$} \\
\hline 2 & $M / 44$ & \multicolumn{3}{|c|}{ At 42 yo ischemic stroke with left hemiparesis; since 43 yo - progressing dementia, positive family history } \\
\hline 3 & $M / 53$ & \multicolumn{3}{|c|}{ Migraine, since 50 yo progressing dementia, unknown family history } \\
\hline 4 & $F / 35$ & \multicolumn{3}{|c|}{$\begin{array}{l}\text { At } 35 \text { yo two seizures attacks, hyperintense changes in cerebral white matter in MRI, positive family history, } \\
\text { confirmed NOTCH3 mutation }\end{array}$} \\
\hline 5 & M/61 & \multicolumn{3}{|c|}{$\begin{array}{l}\text { At } 44 \text { yo ischemic stroke, later } 2 \text { bilateral ischemic strokes, hyperintense changes in the cerebral white matter } \\
\text { in MRI; positive family history - father of patient no. 4, confirmed NOTCH3 mutation }\end{array}$} \\
\hline 6 & M/39 & \multicolumn{3}{|c|}{$\begin{array}{l}\text { At } 33 \text { yo TIA with left hemiparesis and aphasia, normal brain MRI, positive family history - brother of patient } \\
\text { no. } 4 \text {, confirmed NOTCH3 mutation }\end{array}$} \\
\hline 7 & $\mathrm{~F} / 57$ & \multicolumn{3}{|c|}{ Migraine, hyperintense changes in cerebral white matter in MRI, negative family history } \\
\hline 8 & $\mathrm{~F} / 42$ & \multicolumn{3}{|c|}{$\begin{array}{l}\text { Since } 42 \text { yo recurrent TIA, hyperintense changes in the cerebral white matter in MRI, negative family history, } \\
\text { confirmed NOTCH3 mutation }\end{array}$} \\
\hline 9 & $M / 58$ & \multicolumn{3}{|c|}{$\begin{array}{l}\text { Since } 57 \text { yo cognitive disturbances, negative family history, negative genetic test (examined only } 3 \text { NOTCH3 } \\
\text { exons) }\end{array}$} \\
\hline 10 & $M / 44$ & \multicolumn{3}{|c|}{ At 42 yo and 45 yo ischemic strokes with left hemiparesis, positive family history, confirmed NOTCH3 mutation } \\
\hline \multicolumn{5}{|c|}{ Control material } \\
\hline No. & Sex/Age & Clinical data & Sex/Age & Clinical data \\
\hline \multicolumn{5}{|c|}{ Autopsy material } \\
\hline 1 & $\mathrm{~F} / 64$ & Ischemic brainstem stroke & $M / 41$ & Myopathy suspicion \\
\hline 2 & $M / 59$ & Ischemic stroke & $\mathrm{F} / 45$ & Collagenosis suspicion \\
\hline 3 & $M / 57$ & Pancreas carcinoma & $\mathrm{F} / 46$ & Myopathy suspicion \\
\hline 4 & $F / 43$ & Myeloma & $M / 42$ & Vasculitis suspicion \\
\hline 5 & $F / 32$ & Leukemia & $F / 39$ & Vasculitis suspicion \\
\hline
\end{tabular}

acter (Fig. 2F, H, I). It is interesting that in many vessels the immunolabel to integrin $\beta 1$ was better preserved in more luminal than peripheral part of the media (Fig. $2 \mathrm{H}, \mathrm{I}$ ). Frequently, pericellular immune reaction to integrin $\beta 1$ was negative even in microscopically normal but peripherally localized myocytes (Fig. $2 \mathrm{H}, \mathrm{I}$ ). Arterial vessels at a very advanced stage of degeneration demonstrated a loss of or evidently decreased immunoreactivity to integrin $\beta 1$ in the media (Fig. 2G).

Immunolabels to integrin subunits $\alpha_{4}$ and $\beta_{3}$ were weak and similar in CADASIL and controls.

In CADASIL, the above changes in an integrin expression were similar in cerebral, skin and skeletal muscle vessels. That is why statistics were performed together for autopsy and biopsy material. 
A

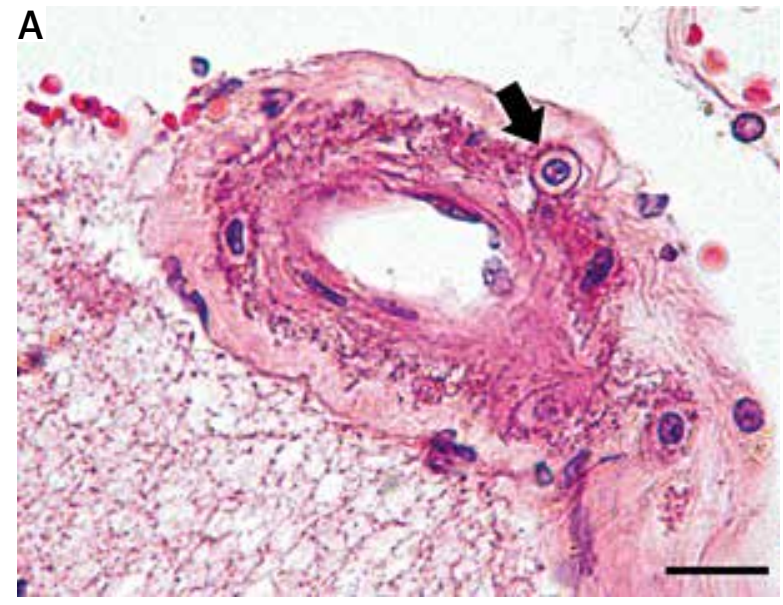

B

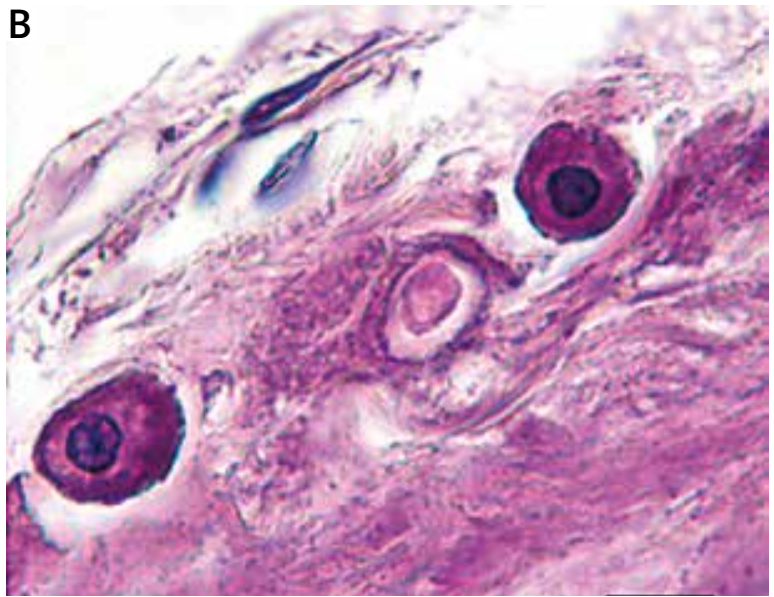

Fig. 1. Rounded vascular smooth muscle cells (VSMC) in the vessel wall in CADASIL; H\&E. A) Meningeal arteriole with basophilic granular degeneration. A single round myocyte with a perinuclear hallo ("fried egg" appearance - arrow) in the vascular media is visible; bar: $50 \mu \mathrm{m}$. B) Fragment of the vascular media with three myocytes. Severely damaged middle myocyte with pale cytoplasm is surrounded by basophilic granular material while two dark cells on its sides are round with clear (empty?) pericellular area; bar: $20 \mu \mathrm{m}$.

\section{Discussion}

One of the characteristic morphological changes observed by us in CADASIL was a round shape of myocytes in the tunica media. This phenomenon has been visible on some figures included in already published CADASIL papers but, surprisingly, it has not received any attention of the authors. In small arteries and arterioles, the media are composed of a layer of smooth muscle cells with circular arrangement. Therefore in normal conditions, on transverse sections through the vessel wall VSMCs have a longitudinal shape. But in CADASIL preserved myocytes were often rounded. Such rounded appearance is characteristic for cells detached from ECM and devoid of any physical influences from the surrounding environment [10]. The cell shape is controlled by the cytoskeleton, its connections with integrins and continuous tension (tensegrity) being a reaction of the cell to applied pressure and interactions with external substrates. Loss of tensegrity leads to cell retraction and probably such phenomenon was observed by us in the CADASIL vascular media.

In the examined CADASIL microvessels, a decreased immune expression of integrin subunit $\beta 1$ in the media was found. The diminished immunolabel to integrin $\beta 1$ was noted even in microscopically normal vessels, which suggests that this alternation is an early change in CADASIL.
In VSMCs, the $\beta 1$ subunit is a compound of 10 different heterodimer integrin receptors, hence it is not possible to define whether its abnormal immune expression, as observed by us, is related to one or more types of the integrin receptors. Moreover, an individual integrin may bind to different components of ECM just as a single matrix component may bind to different integrins. Taking into account this complexity of interactions it is not surprising that integrin-mediated cellular responses are quite varied and multifaceted. Therefore it is difficult to discuss specific consequences of the diminished expression of integrin $\beta 1$ in CADASIL but only its general impact.

CADASIL is due to mutations in the NOTCH3 gene. Integrins constitute a crucial element of the Notch signaling system but the relationship is mutual. On the one hand, transfer of the intracellular domain of the Notch 3 receptor to the cell nucleus leads to unlocking of genes transcription and integrins activation [19]. On the other hand, integrins play an important role in regulation of the Notch 3 receptor activity by mediation of its caveolin-1-dependent endocytosis [7]. Internalization of caveolin-1 inhibits Notch 3 endocytosis and may favor accumulation of the receptor on the surface of VSMCs - the other than GOM deposits morphologic change characteristic for CADASIL.

Integrin $\beta 1$ engagement also results in ligand-independent activation of many different receptors, 

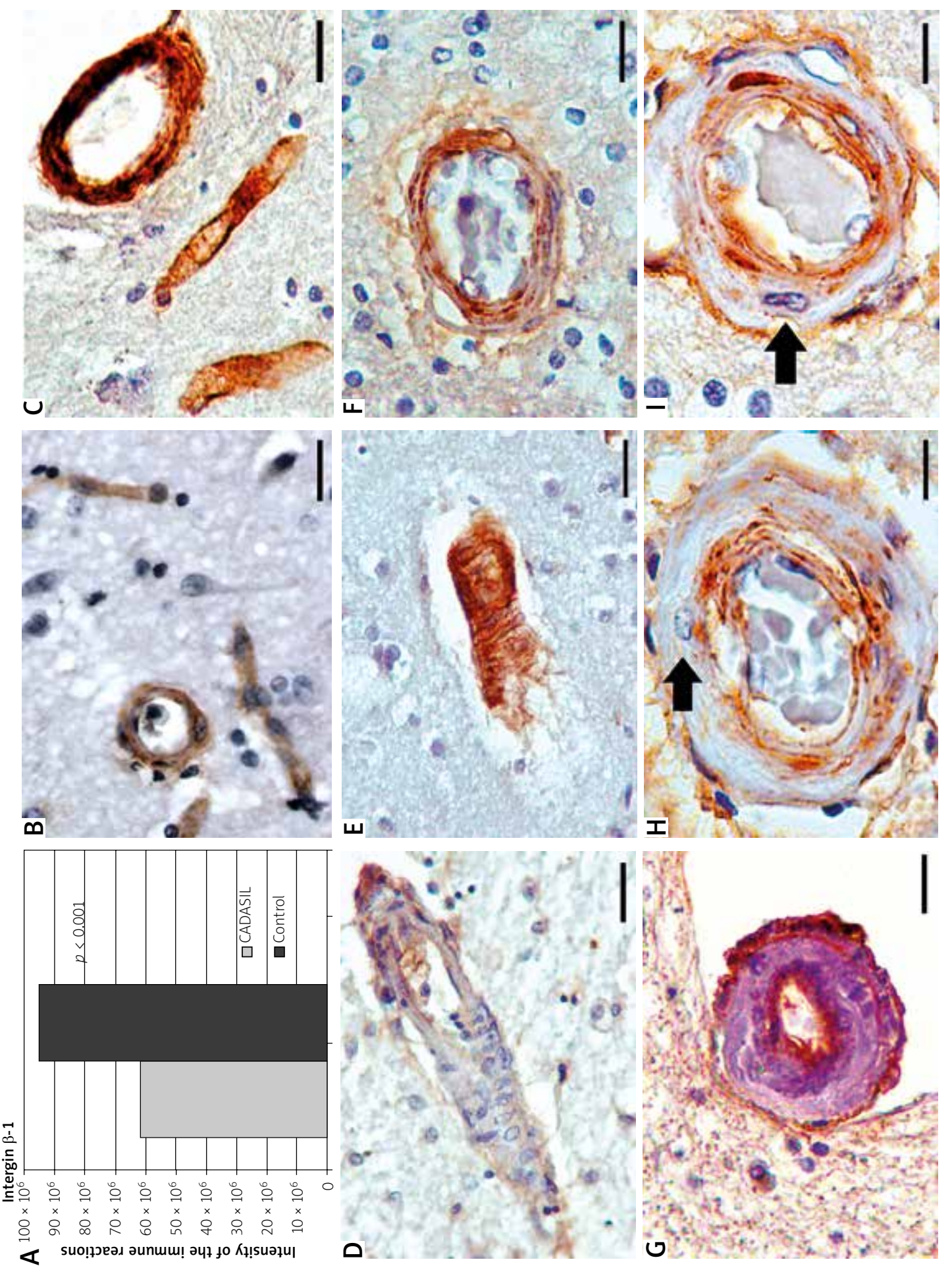

Fig. 2. Immune expression of integrin subunit $\beta 1$ in various sized cerebral vessels in CADASIL and control materials. A) Results of the statistical analysis demonstrate the significant difference $(p<0.001)$ in the intensity of the immunolabel to integrin subunit $\beta 1$ in CADASIL and control cases. B-E) Diminished immune expression of integrin $\beta 1$ in parenchymal small arteries, arterioles and capillary vessels in CADASIL (B,D) and controls (C,E); bars: $100 \mu \mathrm{m}$. F) Structurally normal white matter arteriole with a diminished expression of integrin $\beta 1$, bar: $50 \mu \mathrm{m}$. G) Small meningeal artery at the advanced stage of degeneration. Negative immunoreactivity to integrin $\beta 1$ in the thickened tunica media and positive immunolabel of the adventitia and endothelium; bar: $100 \mu \mathrm{m}$. H, I) Irregular, patchy character of the integrin $\beta 1$ immune expression in small white matter arterioles. Single relatively well preserved vascular smooth muscle cells (VSMC) with immunonegative pericellular reaction (arrows) in the peripheral part of the tunica media are visible; bars: $50 \mu \mathrm{m}$. 
among them epidermal growth factor receptor (EGFR) [18]. In detached cells disengagement of integrin $\beta 1$ leads to down-regulation of EGFR expression culminating in upregulation of death signaling [22]. In the literature, we have not found any information concerning EGFR expression on VSMCs in CADASIL. But mutations in the NOTCH3 gene responsible for development of the disease affect only that part of the Notch 3 receptor which contains EGF repeats motif. Although EGF-like motif is shared by many proteins of diverse functions and its significance is not well defined, one of its functions is mediation of adhesive interactions [22]. Therefore an abnormal integrin $\beta 1$ expression in CADASIL arteries may not only disturb, per se, myocyte adhesion to ECM but also it may have an influence on adhesive interactions mediated by the Notch 3 receptor.

Integrins are involved in regulation of cell viability through their interaction with ECM. They sense mechanical forces arising from contacts with ECM and convert them into intracellular signals leading to gene expression. It was reported that in blood vessels signals undergoing from integrin $\beta 1$ protect VSMCs from apoptosis due to mechanical stress [29]. Moreover, integrins $1 \beta 1, \alpha 2 \beta 1, \alpha 3 \beta 1, \alpha 5 \beta 1, \alpha 6 \beta 1$ (presented on VSMCs surface) activate pro-survival pathways $[2,8]$. One of the integrin-mediated survival signaling pathways occurs through the caveolin-1-mediated binding of integrins to the adaptor protein (protein Shc). This type of integrin binding allows the cell to escape from death by a special type of apoptosis called anoikis [3,28]. Anoikis, a Greek word meaning loss of home or homelessness, is due to loss or inappropriate cell adhesion to ECM. Anoikis is observed both physiologically (in normal skin, in colonic epithelium, in the involuting mammillary glands), as well as in many pathologic conditions such as metastatic spreading and cardiovascular degenerative processes including VSMCS disappearance in aneurysms and varicose veins, extensive loss of vascular cells during cardiovascular infections, cardiac myocyte detachment in heart failure, and plaque rupture in atherosclerosis [4,12,27].

It was demonstrated that in cells undergoing apoptosis the expression of integrin $\beta 1$ is diminished and is about 65\% [14]. A decreased or absent integrin $\beta 1$ expression on VSMCs not only inhibits pro-survival pathways and facilitates their death but can also change the phenotype of myocytes towards synthetic one which is more sensitive to apoptosis [1].
Investigations on the integrin expression on blood vessels showed that a decreased $\beta 1$ expression can disturb vasomotor reactivity $[15,16]$. In experimental investigations, impaired cerebral vasoreactivity in a transgenic mouse model of CADASIL was observed [13]. Also clinical studies on CADASIL patients demonstrated abnormal vasoreactivity $[9,26]$ and a reduced cerebral blood flow $[20,23]$ in the course of the disease. Integrin subunit $\beta 1$ as a part of $\alpha 1 \beta 1$ and $\alpha 5 \beta 1$ integrin receptors is involved in vasoconstriction and transfer of signals originating from ECM and regulating permeability of calcium channels on VSMCs and myocytic voltage value. For these reasons abnormal immune expression of integrin subunit $\beta 1$ as observed by us may result in impaired vasoreactivity. In CADASIL, abnormal vessel mechanoresponse precedes development of morphological changes in vessels and white matter lesion both in patients and in animals [11]. These clinical and experimental observations reinforce our hypothesis that an abnormal integrin $\beta 1$ expression in microvessels is an early phenomenon in CADASIL.

Putting all the data together, we suggest that disturbed expression of integrin subunit $\beta 1$ in CADASIL can be an important part of the disease pathomechanism leading to improper activity of the Notch 3 signaling pathway and VSMCs degeneration and loss via anoikis.

\section{Disclosure}

Authors report no conflict of interest.

\section{References}

1. Abraham S, Kogata N, Fassler R, Adams RH. Integrin beta-1 subunit controls mural cell adhesion, spreading, and blood vessel wall stability. Circ Res 2008; 102: 562-570.

2. Alahari SK, Reddig PJ, Juliano RL. Biological aspects of signal transduction by cell adhesion receptors. Int Rev Cytol 2002; 220: 145-184.

3. Barberis L, Wary KK, Fiucci G, Liu F, Hirsch E, Brancaccio M, Altruda F, Tarone G, Giancotti FG. Distinct roles of the adaptor protein Shc and focal adhesion kinase in integrin signaling to ERK. J Biol Chem 2000; 275: 36532-36540.

4. Beaufort N, Corvazier E, Hervieu A, Choqueux C, Dussiot M, Louedec L, Cady A, de Bentzmann S, Michel JB, Pidard D. The thermolysin-like metalloproteinase and virulence factor LasB from pathogenic Pseudomonas aeruginosa induces anoikis of human vascular cells. Cell Microbiol 2011; 13: 1149-1167.

5. Davis MJ, Wu X, Nurkiewicz TR, Kawasaki J Davis GE, Gui P, Hill MA, Wilson E. Integrins and mechanotransduction of the vascular myogenic tone. Am J Physiol Circ Physiol 2001; 280: 1427-1433. 
6. Davous P. CADASIL: a review with proposed diagnostic criteria. Eur J Neurol 1998; 5: 219-233.

7. Echarri A, Del Pozo MA. Caveolae internalization regulates integrin-dependent signaling pathways. Cell Cycle 2006; 5: 21792182.

8. Giancotti FG. Complexity and specificity of integrin signalling. Nat Cell Biol 2000; 2: E13-14.

9. Hussain M, Singhal S, Markus H, Singer DR. Abnormal vasoconstrictor responses of angiotensin II and noradrenaline in isolated small arteries from patients with CADASIL. Stroke 2004; 35 853-858.

10. Ingber DE. Tensegrity I. Cell structure and hierarchical systems biology. J Cell Sci 2003; 116: 1157-1173.

11. Joutel A, Monet-Leprêtre M, Gosele C, Baron-Menguy C, Hammes A, Schmidt S, Lemaire-Carrette B, Domenga V, Schedl A, Lacombe P, Norbert Hubner N. Cerebrovascular dysfunction and microcirculation rarefaction precede white matter lesions in a mouse genetic model of cerebral ischemic small vessel disease. J Clin Invest 2010; 120: 433-445.

12. Kockx MM, Herman AG. Apoptosis in atherosclerosis: beneficial or detrimental? Cardiovasc Res 2000; 45: 736-746.

13. Lacombe P, Oligo C, Domenga V, Tournier-Lasserve E, Joutel A. Impaired cerebral vasoreactivity in a transgenic mouse model of cerebral autosomal dominant arteriopathy with subcortical infarcts and leukoencephalopathy. Stroke 2005; 36: 1053-1058.

14. Levkau B, Kenagy RD, Karsan A, Weitkamp B, Clowes AW, Ross R, Raines EW. Activation of metalloproteinases and their association with integrins: an auxiliary apoptotic pathway in human endothelial cells. Cell Death Differ 2002; 9: 1360-1367.

15. Martinez-Lemus LA, Sun Z, Trache A, Trzciakowski JP, Meininger GA. Integrins and regulation of the microcirculation: from arterioles to molecular studies using atomic force microscopy. Microcirculation 2005; 12: 99-112.

16. Martinez-Lemus LA, Wu X, Wilson E, Hill MA, Davis GE, Davis MJ, Meininger GA. Integrins as unique receptors for vascular control. J Vasc Res 2003; 40: 211-233.

17. Michel JB. Anoikis in the cardiovascular system. Known and unknown extracellular mediators. Arterioscler Thromb Vasc Bio 2003; 23: 2146-2154

18. Moro L, Venturino M, Bozzo C, Silengo L, Altruda F, Beguinot L, Tarone G, Defilippi P. Integrins induce activation of EGF receptor: role in MAP kinase induction and adhesion-dependent cell survival. EMBO J 1998; 17: 6622-6632.

19. Morrow D, Scheller A, Birney YA, Sweeney C, Guha S Cummins PM, Murphy R, Walls D, Redmond EM, Cahill PA. Notch-mediated CBF-1/RBP-Jk-dependent regulation of human vascular smooth muscle cell phenotype in vitro. Am J Cell Physiol 2005; 289: 11881196.

20. Pfefferkorn T, von Stuckrad-Barre S, Herzog J, Gasser T, Hamann GF, Dichgans M. Reduced cerebrovascular CO2 reactivity in CADASIL: a transcranial Doppler sonography study. Stroke 2001; 32: 17-21.

21. Reed RK, Berg A, Gjerde EA, Rubin K. Control of interstitial fluid pressure: Role of beta1-integrins. Semin Nephrol 2001; 21: 222 230.

22. Sakamoto K, Sheng Chao W, Katsube K, Yamaguchi A. Distinct roles of EGF repeats for the Notch signaling system. Exp Cell Res 2005; 302: 281-291.
23. Singhal S, Markus HS. Cerebrovascular reactivity and dynamic autoregulation in nondemented patients with CADASIL (cerebral autosomal dominant arteriopathy with subcortical infarcts and leukoencephalopathy). J Neurol 2005; 252: 163-167.

24. Stupack DG. Integrins as a distinct subtype of dependence receptors. Cell Death Differ 2005; 12: 1021-1030.

25. Theocharis AD, Skandalis SS, Gialeli Ch, Karamanos NK. Extracellular matrix structure. Adv Drug Deliv Rev 2016; 97: 4-27.

26. Tuominen S, Miao Q, Kurki T, Tuisku S, Poyhonen M, Kalimo H, Viitanen M, Sipilä HT, Bergman J, Rinne JO. Positron emission tomography examination of cerebral blood flow and glucose metabolism in young CADASIL patients. Stroke 2004; 35: 10631067.

27. Walsh K, Smith RC, Kim HS. Vascular cell apoptosis in remodeling, restenosis, and plaque rupture. Circ Res 2000; 87: 184-188.

28. Wary KK, Mariotti A, Zurzolo C, Giancotti FG. A requirement for caveolin-1 and associated kinase Fyn in integrin and associated kinase Fyn in integrin signaling and anchorage-dependent cell growth. Cell 1998; 94: 625-634.

29. Wernig F, Mayr M, Xu Q. Mechanical stretch-induced apoptosis in smooth muscle cells is mediated by beta1-integrin signaling pathways. Hypertension 2003; 41: 903-911. 